Visões da
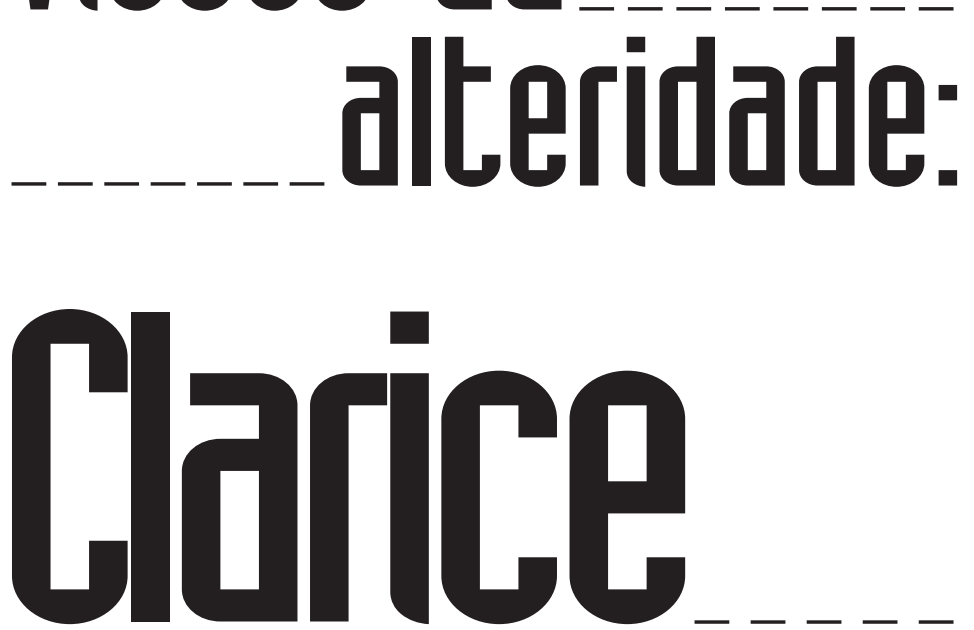

lispector

\section{e Maurice}
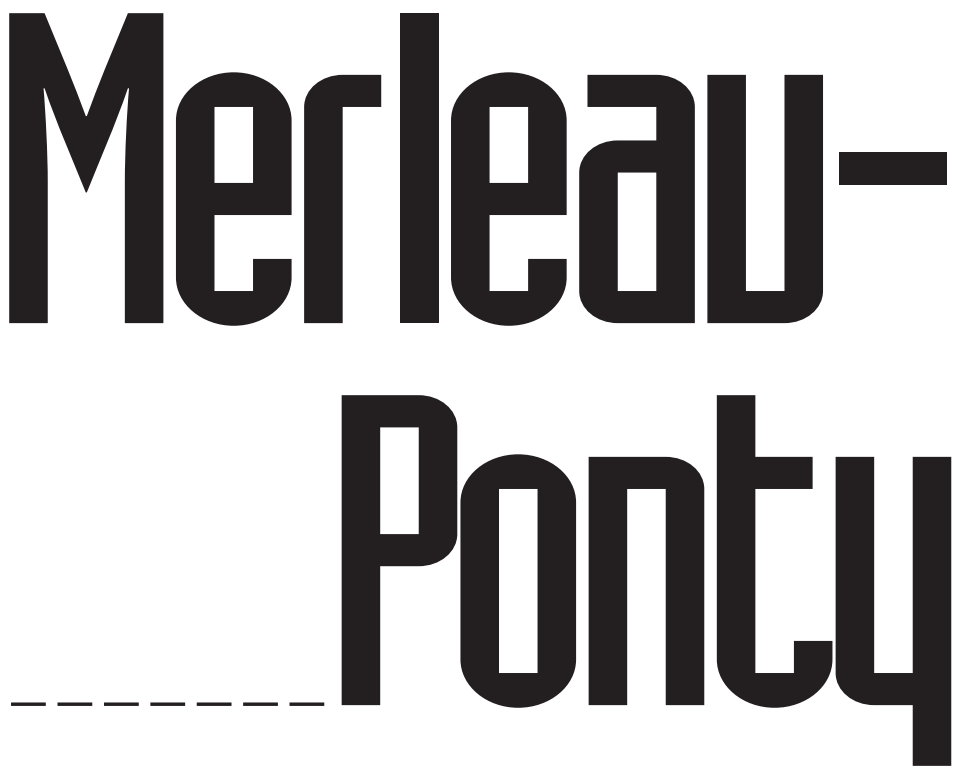

pector. É, também, o fio temático condutor que permite vincular entre si os romances, contos e crônicas que compõem o conjunto relativamente vasto de escritos da autora. Neles, de fato, desfila uma legião de seres que nossa cultura costuma designar como "outros": tanto aqueles com quem cada indivíduo tece sua vida de relações afetivas, sobretudo no círculo familiar mais estreito; como aqueles sobre quem pesa a marca social de subalternidade, marginalidade ou exclusão: mulheres, animais, adolescentes, velhos, loucos, primitivos e pobres.

Perto do Coração Selvagem, romance com que Clarice estréia em 1944, reflete sobre o processo de constituição da identidade feminina, através do aprendizado de vida da heroína Joana. Suas vivências de menina e mulher se fazem pela convivência, muitas vezes penosa, com aqueles que lhe servem de espelho onde se conhecer, por semelhança ou antagonismo. Na infância, o pai, a mãe, a tia, o professor. Como adulta, o marido, a amante do marido, seu próprio amante.

No fim da carreira e da vida de Clarice, em 1977, o tema retorna numa peculiar constelação de sentidos. A Hora da Estre$l a$, obra de denúncia franca do caráter excludente da sociedade brasileira, põe em primeiro plano não mais uma mulher de inteligência aguda e situação econômica confortável, como Joana. O destaque vai agora para Macabéa, uma nordestina absolutamente despossuída: sem dinheiro, sem família, sem atrativos femininos, sem cultura, quase sem fala. Mas essa nãopessoa tem sua des-identidade definida, de novo, pelo confronto com os seus "outros": o namorado, a colega de trabalho, o patrão e, sobretudo, o narrador de sua história, intelectual de classe média, que vê nela uma espécie de avesso de si-mesmo. Entre essas duas obras, inicial e final, outras merecem destaque no que se refere à constituição do tema da alteridade. Limito-me às mais conhecidas. 
Laços de Família, de 1960, reúne contos particularmente interessantes nesse sentido. Em "O Crime do Professor de Matemática" e "O Búfalo", o "outro" aparece como animal: no primeiro caso, um cão, no segundo, um búfalo. E reaparece em "A Menor Mulher do Mundo", novamente como mulher mas também e sobretudo como "primitivo". A "menor mulher" do título é uma anã negra africana, vivendo em estágio tribal muito próximo da animalidade.

Em 1964, Clarice publica A Paixão Segundo G.H., tido como ponto culminante de sua carreira. Aí também se assiste a um confronto demorado entre um "eu”, a escultora G. H., narradora e personagem central, e seu "outro", no caso uma "outra": a barata que G. H. esmagara contra a porta do guarda-roupa, no quarto de empregada de seu apartamento.

Os casos mencionados, bem como o restante da obra da escritora, permitem ver não somente o rosto com que ela desenha a alteridade. Mas também e principalmente o modo como "eu" e "outro" se relacionam numa dinâmica de oposição e identificação simultâneas. Ou seja: não só os pólos do "eu" e do "outro" não se excluem como, ao contrário, cada um é condição de possibilidade de existência do outro.

Perto do Coração Selvagem se centra na consciência da personagem principal, disso resultando uma atmosfera solipsista já que o mundo à volta de Joana parece emanação sua. Por esse motivo, aliás, Alvaro Lins, um dos primeiros críticos do romance, afirmou de imediato a influência, sobre Clarice, da novelística de Joyce e Virgínia Wolf. E de fato, do romance ressalta a impressão forte de um "eu" fechado em seu próprio espaço, onde os outros - o pai, a mãe, o professor, o marido, etc. - só entrariam depois de devidamente assimilados. Entretanto, é verdade também que o conflito interior de Joana, motivado pela busca incessante de algo que sempre lhe escapa, mostra nela a coexistência de vários “eus”. E assim se compõe um psiquismo multifacetado, permitindo indiretamente ver, em cada faceta, cada um dos outros com quem ela se relaciona.

N'A Hora da Estrela, o contraponto entre "eu" e "outro" se encontra mais nitidamente desenhado. Entre Rodrigo, o narrador-personagem, e Macabéa, a nordestina cuja história ele conta, estabelecese uma complexa dinâmica de identificação e estranhamento. Rodrigo se apresenta como um intelectual, ostentando conhecimentos da alta cultura. E nisso é o oposto absoluto de Macabéa. Mas a certa altura de seu relato, ao ver a moça se olhando no espelho, ele vê também aparecer aí o seu próprio rosto (1). E depois confessa com todas as letras que "é paixão minha ser o outro. No caso a outra. Estremeço esquálido igual a ela" (2).

Semelhante é a dinâmica das relações entre a barata e G. H. Sua náusea é a manifestação física de uma força de repulsão que, no plano do discurso, responde por um relato permanentemente em vias de se interromper. Mas tal interrupção sinaliza também ambiguamente a experiência da destruição da fronteira que separa G. H., enquanto ser humano, da barata, enclausurada em sua animalidade. Pois os espaços de ausência da fala-relato correspondem aos da experiência viva de comunhão de G. $\mathrm{H}$. com a barata.

Do mesmo assunto trata a novela "Os Desastres de Sofia”, incluída no volume A Legião Estrangeira, de 1964. Aí se conta a história das relações ásperas entre uma menina, em vias de se tornar mulher, e seu professor, em quem ela encontra a figura masculina a partir da qual construir sua feminilidade. Se ambos de início se relacionam de maneira tensa é porque se encontram em campos polarizados: ele, adulto, homem, professor. Ela, criança, mulher, aprendiz. No entanto, é justamente do âmago dessas oposições que brota a experiência da dissolução das fronteiras que os separam. Por um átimo, é ele quem, voltando a ser criança diante dela, sorri "em vitória infantil", pondo nesse sorriso "sua aplicação de aluno lento”. E ela, que pensa que lhe dissera uma mentira, fica "sem coragem de desiludi-lo", sentindo-se culpada
REGINA LÚCIA PONTIERI é professora do Departamento de Teoria Literária da FFLCHUSP e autora de Clarice Lispector - uma Poética do Olhar (Ateliê Editorial).
Clarice Lispector, A Hora da Estrela, $7 \mathrm{a}$ ed. Rio de laneiro, Nova Fronteira, 1984, p. 29

2 Idem, ibidem, p. 37 
Idem, A Legião Estrangeira, Rio de Janeiro, Editora do Autor, 1964, pp. 23-4.

4 Benedito Nunes, O Drama da Linguagem - uma Leitura de Clarice Lispector São Paulo, Ática, 1989, pp. 100-1.

5 Jean Paul Sartre, L'Être et le Néant - Essai d'Ontologie Phénoménologique, $18^{\mathrm{eme}}$ ed. Paris, Gallimard, 1949 Bibliothèque des Idées, p. 283 A tradução é minho.

6 Maurice Merleau-Ponty, "OPro blema da Existência do Outro Segundo Husserl", in MerleauPonty na Sorbonne: Resumo de Cursos: 1949-1952: Filosofia e Linguagem, trad. Constança $M$ Cesar Campinas, Papirus, 1990, pp. 45 a 48

7 Apud José Américo Pessanha, "Bachelard e Monet: o Olho "Mão" in Adauto Novaes (org.l, O Olhar, São Paulo, Companhia das Letras, 1988 p. 157.

8 Esclarecendo o trabalho filosó fico de compreensão do visíve e do sensível, Merleau-Ponty diz que o filósofo "somente suspende a visão bruta para transpóla para a ordem do expresso mas essa visão "permanece se modelo ou sua medida" e assim "é sobre ela que deve abrirse a rede de significações que a filosofia organiza para reconquistá-la". Em seguida, vem a crítica direta a Descar tes: "Não cabe, pois, supor inexistente o que era visto ou sentido e também a visão e o sentir substituindo-os, contorme a palavra de Descartes, pelo 'pensamento de ver e de sentir"'. O Visível e o Invisível, trad. osé A. Gianotti e Armando M. Oliveira, São Paulo, Perspectiva, 1984, pp. 44-5. como um adulto que enganasse uma criança (3).

Nas cenas claricianas de confronto entre eu e outro sobressai ainda, além do aspecto de reversibilidade da relação, um outro traço característico: a natureza eminentemente visual e por vezes também gustativa do contato. Em muitos dos casos citados encena-se o trabalho mais ou menos intenso e demorado de um olhar examinando seu objeto. Em alguns deles, esse gesto estabelece liames significativos com a atividade de comer. A ponto de, no caso de A Paixão Segundo G. H., haver mesmo clara promiscuidade entre ambos. Pois G. H., não só literalmente come a barata, como ainda a come com os olhos, tal a atenção que põe em olhá-la.

Desse olhar atento se faz também a cena do encontro entre o pesquisador francês, Marcel Pretre, e Pequena Flor, a africana de quarenta e cinco centímetros, que ele descobrira no coração da África Central. O vigor do olhar analítico-cartesiano com que Marcel disseca a mulherzinha só encontra paralelo no "riso bestial" com que ela o desconcerta. Assim também, em “O Búfalo", uma mulher entra no Jardim Zoológico à procura de parceiro com quem refazer a relação de ódio e amor pelo homem que a abandonara. Percorre as jaulas com olhos alertas e ansiosos, até finalmente encontrar, no búfalo de olhos injetados de sangue, o intenso ódio procurado.

O caráter metafísico da indagação clariciana, sondando o sentido e os limites do eu e do estar no mundo, cedo levou seus leitores a identificarem nela ecos do existencialismo sartriano. Benedito Nunes, crítico de formação filosófica e um dos primeiros grandes estudiosos da obra da escritora, foi também o primeiro e chamar a atenção para as relações possíveis entre Clarice e Sartre. Sobretudo quanto ao papel da experiência da náusea, que em ambos sinalizaria a tomada de consciência da existência bruta. Mas Nunes também apontara uma diferença básica: “o valor da náusea em Clarice", diz ele, "remete-nos a uma atitude perante as coisas e o ser em geral, que difere da sartriana", pois nela "a pers- pectiva mística suplanta a existencial inerente à temática da obra” (4).

Ora, em Sartre a relação entre eu e outro se faz também pelo olhar. Mas de tal modo que o eu olhado é aniquilado pela liberdade do outro que, transcendendo-o, faz dele um objeto. Para o filósofo de L'Être et le Néant"o outro não é somente aquele que eu vejo, mas aquele que me vê. Eu viso o outro enquanto um sistema ligado de experiências fora de minha possibilidade de alcance, no qual eu figuro como um objeto entre outros". Além disso, "o outro... se apresenta, num certo sentido, como a negação radical da minha experiência, já que ele é aquele para quem eu sou não sujeito mas objeto" (5).

A reflexão de Merleau-Ponty, em muitos aspectos aparentada à de Sartre, diverge dela na questão da alteridade. Ponty observa que o que impediu a fenomenologia husserliana de explicitar a existência do outro foi a recusa de abrir mão do conceito cartesiano de cogito, pelo qual a consciência é sempre consciência de si, sendo, assim, somente possível ver o outro como um outro eu (6). Observação semelhante caberia também para Sartre, em quem, por isso, Gaston Bachelard vê uma tendência intelectualista e ocularista, responsável pela repugnância que lhe causam o viscoso e o pastoso, elementos pertinentes à esfera do tátil, do que o Roquentin de La Nausée é exemplo claro (7)

Merleau-Ponty repropõe a relação entre eu e outro de modo a superar a visão cartesiana do sujeito que, distanciado do mundo, não pode senão sobrevoá-lo (8). Em Le Visible et l'Invisible, o filósofo vê no corpo, enquanto ponto de junção entre vidente e visível, a possibilidade de efetuar tal superação. Pois o corpo, diz ele, "é um ser de duas faces, de um lado, coisa entre as coisas e, de outro, aquilo que as vê e toca", pertencendo, assim, simultaneamente à ordem do sujeito e à do objeto. Se o corpo apalpa e vê o mundo que lhe é dado como campo de visibilidade, não é porque os visíveis estejam diante dele como objetos. Mas somente porque, "pertencendo à mesma família, sendo, ele próprio, visível e 
tangível, utiliza seu ser como meio para participar do deles", e também “porque cada um dos dois seres é para o outro o arquétipo, e os corpos pertencem à ordem das coisas assim como o mundo é a carne universal"' (9).

Justamente: o ponto em que se tocam a filosofia de Merleau-Ponty e a ficção de Clarice Lispector parece estar na identificação de uma "carne universal", de que comungariam todos os seres. As obras de Clarice glosam, cada uma a seu modo, o mote de Joana, “tudo é um” (10); que é idêntico à constatação de G. H. de que "tudo está vivo e é feito do mesmo" (11); e à crença de Rodrigo, em que "todos nós somos um” (12). Nela, a experiência da alteridade mostra que o outro não é, como para Sartre, um outro eu. Ao contrário, o eu é que se reduz à condição de "outro do outro". Literalmente: "eu antes tinha querido ser os outros para conhecer o que não era eu. Entendi então que eu já tinha sido os outros e isso era fácil. Minha experiência maior seria ser o outro dos outros: e o outro dos outros era eu" (13).

No entanto, entre Clarice e MerleauPonty notam-se também diferenças, uma das quais merece, no âmbito deste estudo, atenção particular. Referindo-se ao corpo como partícipe da carne do mundo, o filósofo enfatiza que ele é não somente vidente e visível, como ainda tangente e tangível. Ou seja, não há reversibilidade e cruzamento somente entre o que é olhado mas entre o olhar e o tocar: "todo visível é moldado no sensível, todo ser táctil está voltado de alguma maneira à visibilidade, havendo, assim, imbricação e cruzamento, não apenas entre o que é tocado e quem toca, mas também entre o tangível e o visível que está nele incrustado" (14). A ênfase posta por ele no sentido do tato reporta-se ao trabalho artístico do pintor que empresta seu corpo ao mundo, transformando-o em pintura (15). Em alguns de seus escritos, Ponty busca em Cézanne uma experiência exemplar de parentesco entre eu e mundo expressando-se, através do tato, como realidade pictórica corporal.

De modo semelhante, Clarice explora o estreito parentesco entre as várias sensações. Donde, com freqüência, a crítica observa, em vista do acúmulo de sinestesias em sua escritura, seu caráter eminentemente corporal. No entanto, apontar o uso de metáforas sinestésicas ou mesmo o alto teor de descritividade de sua obra não basta para tocar o cerne da questão, uma vez que sinestesias e descrição são técnicas freqüentes no discurso literário. A forte presença da corporeidade se mostra sobretudo na contaminação entre os sentidos visual e gustativo. Em A Paixão Segundo G.H., é da integração e fusão entre ver e comer que surge um relato fundamente enraizado na experiência do corpo. Tanto que a escritura com que $G$. $H$. recupera sua vivência agônica de confronto com a barata possui o mesmo ritmo tenso do corpo que extertora em vômito. Como o corpo de G. H., expulsando de si o corpo da barata, depois de pôlo na boca.

Ou seja: o filósofo elege a sensação tátil como contrapeso da importância que durante séculos foi atribuída ao olhar, como metáfora privilegiada da atividade de conhecimento (16). Isso, aliás, é o que também sucede com outro fenomenólogo francês, já citado. Gaston Bachelard recorre ao imaginário material, produto do trabalho pictórico ou escultórico das mãos, como meio de ultrapassar o imaginário visual, segundo ele intelectualista e abstrativo, subjacente ao cogito cartesiano.

A ficcionista, por seu lado, parece propor um gesto ainda mais radical, por ir mais diretamente à raiz das coisas. Pois se o corpo é a raiz, então o ato de comer, mais do que o de tocar, é o operador por excelência da assimilação entre sujeito e mundo e entre eu e outro. A mão laboriosa, tocando a carne das coisas, abole a distância que vai do olhar ao olhado. Mas entre a mão que toca e aquilo que ela toca se mantém, fina que seja, a película de garantia de separação. Pelo trabalho da boca voraz, o que se dá não é só superação da distância. É, ainda, assimilação. É também a metamorfose pela qual tudo pode vir a ser um, do mesmo modo como, reversivelmente, do um rebrotam todas as diferenças, já que a mesma boca
9 Idem, pp. 133-4.
10 Clarice Lispector, Perto do Co-
ração Selvagem, 5a ed., Rio
de Janeiro, José Olympio,
1974, p. 42.
11 Idem, A Paixão Segundo G.
H., edição crítica coord. por
Benedito Nunes, Paris,
Association Archives de la
littérature latino-américaine,
des Caraibes et africaine du
XXe siècle, Brasília, CNPq, P.
47.

12 ldem, A Hora da Estrela, op cit., p. 18.

13 Idem, A Legião Estrangeira, op cit., p. 142.

14 M. Merleau-Ponty, O Visivel e o Invisível, op. cit., p. 131.

15 ldem, O Otho e o Espírito, São Paulo, Abril Cultural, Os Pensadores, vol. XLI, 1975, p 278

16 Para esse assunto, cf. a coletânea citada, O Olhar 
que engole também vomita. E é assim que, em Clarice, o eu perde seu privilégio de ponto de partida, perdendo-se por um instante no mundo das outridades como mais um outro, aliás “o outro do outro".

\section{- •}

Resta registrar uma hipótese sobre o que teria possibilitado à ficcionista o gesto de radicalidade com o qual, a seu modo, ela parece cumprir mais cabalmente a tarefa proposta por Husserl, de voltar às próprias coisas.

Diversamente dos filósofos mencionados, os lugares ideológicos de onde Clarice fala são aqueles onde tradicionalmente se têm confinado os outros, isto é, os subalternos e excluídos. A começar do fato de pertencer a uma família de judeus pobres (17). Ucraniana por nascimento, ela vem ao mundo portanto numa região periférica a outra periferia, a da Rússia com relação à Europa Ocidental. Emigrando com os pais aos dois meses de idade, chega a Alagoas, um dos estados mais pobres do Nordeste brasileiro. Ou seja, encontra-se agora na periferia da periferia de um país periférico. Sua infância, conforme ela mesma relata em crônicas, é marcada por experiências de carência de vários tipos, inclusive pela morte precoce da mãe. Casada muito jovem, sua vida e o trabalho de escritora são submetidos ao destino de esposa e mãe. As marchas e contramarchas da carreira diplomática do marido a obrigam a inúmeras viagens, quando então conhece alguns países centrais, onde escreve vários de seus livros: reside primeiro na Itália, depois na Suíça, em seguida na Inglaterra, e finalmente nos Estados Unidos.

Alguns anos depois, já separada do

17 Para os dados de biografia de Clarice Lispector, cf.: Nádia B. Gotlib, Clarice-Uma Vida que se Conta, São Paulo, Ática 1995.

18 Clarice Lispector, A Descober ta do Mundo, Rio de Janeiro Nova Fronteira, 1984, p. 270

19 M. Merleau-Ponty, A Dúvida de Cézanne, São Paulo, Abri Cultural, Os Pensadores, vol. $\mathrm{XLI}, 1975, \mathrm{pp}, 311-2$ do de natureza e ainda capaz de rir de pura alegria de estar viva. Assim, ao escolher os lugares originais e originários, aqueles onde localizar as raízes da espécie humana e as do indivíduo, Clarice aponta primeiro para a África, berço da humanidade. Daí provêm tanto Pequena Flor como a barata, que G. H. acha parecida com uma rainha africana. Depois para Alagoas, o quase-berço da própria escritora e lugar de nascimento de Macabéa, aquela que, sendo o avesso de Rodrigo, é também alter ego de Clarice Lispector, que se assume como o verdadeiro autor de A Hora da Estrela.

Discorrendo sobre as relações entre a pintura de Cézanne e sua biografia, Merleau-Ponty afirma que os acidentes da vida do artista são “o texto que, de sua parte, a natureza e a história lhe doaram para decifrar. Proporcionaram apenas o sentido literal da obra. As criações do artista, como aliás as decisões livres do homem, impõem a este dado um sentido figurado que antes delas não existia”. Ainda assim, diz ele, essa liberdade não deve ser entendida como força abstrata pois, se a vida não explica a obra, ambas se comunicam. De tal modo que "esta obra a fazer exigia esta vida" (19).

No que se refere a Clarice, as relações entre vida e obra são muito claras para não chamarem a atenção. Sua experiência de mulher que franqueou várias fronteiras físicas e sociais deu-lhe a matéria com que construir a imagem da alteridade como retrato da exclusão. Mas de modo a não limitar tal retrato ao excluído tido como próprio de um país periférico como o Brasil. Pois se Macabéa é um dos grandes emblemas da obra de Clarice, é-o tanto quanto baratas, galinhas, donas-de-casa, velhas e loucas que, graças a ela, ganharam destaque ficcional. Se sua novelística está entre as mais importantes da literatura brasileira e ganha reconhecimento cada vez maior fora do país, isso se deve ao modo como ela soube tirar, da peculiaridade de sua experiência vivida, a matéria com que dar voz ficcional e universalidade à particularidade onde nossas ideologias segregacionistas têm confinado os outros. 